\title{
Assessment of HIV/AIDS and Life Skills Delivery in Primary Schools in Tanzania
}

\author{
Bernadetha Gabriel Rushahu ${ }^{1, *}$ \\ ${ }^{1}$ Faculty of Educational and Social Sciences, Institute of Education, Carl von Ossietzky University of Oldenburg, \\ Oldenburg 26129, Germany \\ *Correspondence: Kennedystr. 44, II. RE., Oldenburg 26129, Germany. E-mail: \\ brushahu@gmail.com/bernadetha.gabriel.rushahu@uni-oldenburg.de
}

Received: December 17, 2014

Accepted: January 21, $2015 \quad$ Online Published: February 13, 2015

doi:10.5430/wje.v5n1p131

URL: http://dx.doi.org/10.5430/wje.v5n1p131

\begin{abstract}
This study was conducted to assess the effectiveness of HIV/AIDS and the Life Skills Education delivery in primary schools in Tanzania. Specifically the study investigated pupils' views about the effect of HIV/AIDS and Life Skills teaching in primary schools in Tanzania; assessed pupils' knowledge related to HIV/AIDS and Life Skills education, and the effects of pupils' background characteristics on their knowledge about HIV/AIDS and Life Skills education. The study used mainly a questionnaire as the data collection instrument and involved 450 standard V, VI, and VII pupils from 10 schools in Morogoro Municipality. Findings showed that, though significant majority of pupils reported to have been taught about HIV/AIDS and related subjects, majority of them demonstrated a very low level of knowledge about HIV/AIDS. This raised some questions about the effectiveness of HIV/AIDS and Life Skills education in schools. On the basis of the findings of this study, it is recommended that there should be a review of the school curriculum with a view of strengthening the teaching of HIV/AIDS and Life Skills education.
\end{abstract}

Keywords: HIV/AIDS; life skills education; primary school pupils

\section{Introduction}

In Sub-Saharan Africa, the HIV/AIDS epidemic continues to exert a wide range of negative impacts on the demographic factors of population, affecting age structure, dependency ratio, economy, health care and education. It is estimated that more than two-thirds (70\%) of all the 35 million people living with HIV in the world are in this region (UNAIDS/WHO, 2014). The region has just over 10 percent of the world's population, but constitutes 70 percent of all people living with HIV worldwide. An estimated 2.I million adults and children became infected with HIV during 2013; this brought the total number of people living with HIV/AIDS in the region to 24.7 million (UNAIDS/WHO, 2014).

Tanzania is among the countries in the Sub-Saharan African region that has the highest levels of HIV infections. It is estimated that 1.6 million people were living with HIV by the end of 2013, with the HIV prevalence rate of 5.0 percent among adults aged 15-49 (UNAIDS, 2013). Young people are the most affected by HIV/AIDS epidemic in Tanzania. For example, it is estimated that more than 60 percent of all new HIV infections in Tanzania occur among young people aged 15-24 (TACAIDS, NBS \& ORC Macro, 2005). The HIV/AIDS situation by 2013 is illustrated in Table 1. 
Table 1. HIV AND AIDS in Tanzania

\begin{tabular}{lc}
\hline Population & $49,253,000$ \\
\hline People living with HIV/AIDS & $1,400,000$ \\
Adult aged 15 and up living with HIV & $1,200,000$ \\
Women (aged 15+) with HIV/AIDS & 690,000 \\
Children with HIV/AIDS, (0-14) & 250,000 \\
Orphans due to AIDS aged (0-17) & $1,200,000$ \\
Adult HIV prevalence 15-49 (\%), & $5.0 \%$ \\
AIDS Deaths, & 78,000 \\
\hline
\end{tabular}

Source: Epidemiological Facts Sheet on HIV/AIDS (UNAIDS/WHO, 2013)

Following the upward trend in HIV infection among young people, the Government of the United Republic of Tanzania put in place several strategies to address the pandemic, including, for example, declaring the HIV/AIDS epidemic a national disaster (URT, 2001), which was subsequently followed by the formulation of the Tanzania Commission for AIDS (TACAIDS) in 2001 under the Prime Ministers' Office. This was in recognition of the fact that HIV/AIDS is not only a health issue, but also a serious development problem which requires concerted efforts by all sectors, including the private sector, Non-Governmental Organizations (NGOs) and religious groups (NACP, 2004). Furthermore, the HIV/AIDS epidemic has been given a high profile in all sectors in the country. Within the education sector, there have been various efforts to control the spread of HIV/AIDS.

The fight against HIV/AIDS is thus one of the priorities of the Ministry of Education and Vocational Training (MoEVT) which developed a strategic plan for HIV/AIDS 2003- 2007 as well as the Guidelines for Implementing the HIV/AIDS and Life Skills Education programme in schools (URT, 2004). The Guidelines were first developed in 1996 and revised in 2002 to enable the MoEVT and other educational actors to plan, implement and evaluate the efforts better for efficient and effective management, administration and financing of the school HIV/AIDS and Life-Skills education programme (URT, 2004). These Guidelines have been revised to match and closely observe the principles of the Tanzania Education and Training Policy (1995) and those of the National Policy on HIV/AIDS (2001). The Guidelines state that HIV/AIDS and other aspects of sex education will be covered in the Social Studies and Science subjects in primary school syllabi and Biology and Civics for secondary schools (URT, 2004).

In both developed and developing countries including Tanzania many studies have reported that a majority of youth starting with those in primary schools are sexually active and have suffered serious consequences due to unprotected sexual intercourse, including unwanted pregnancy, sexually transmitted infections (STIs), HIV infections and other psychological and socio-economic problems associated with these conditions (Mbonile \& Kayombo, 2008; WHO/UNAIDS, 2007; Booler \& Aggleton, 2005; Muhondwa, 1999; Mwasandube, 1999; Lugoe, 1996).

In response to the effects of HIV/AIDS and other sexual health problems among young people in Tanzania, the MoEVT introduced the Guidelines for HIV/AIDS and Life Skills education in schools that were aimed at mainstreaming the teaching of HIV/AIDS and Life Skills education in schools. Nevertheless, little research has been done to assess the effectiveness of HIV/AIDS and Life skills education delivery in primary schools in Tanzania. It is, for example, not clear how much of the HIV/AIDS and Life Skills education is covered and how it is delivered in schools. This study intended to assess the effectiveness of the level and mode of HIV/AIDS and Life-Skills education delivery in schools.

\section{Conceptual and Theoretical Underpinnings}

\subsection{The Aim of HIV/AIDS and Life Skills Education}

HIV/AIDS and Life Skills education needs to impart to children the coping resources and personal and social competences in a supportive learning environment (UNESCO, 2009). Furthermore, the education focuses on imparting knowledge in relation to decision making, problem solving, creative thinking, interpersonal relationship skills, self-awareness, care in coping with emotion and coping with stress as one lives with HIV infection (UNESCO, 2009 Lugoe, 1996). Thus HIV/AIDS and life skills education aims at minimizing young people's involvement in risky behaviours through instilling and maximising knowledge in adolescents on the sexual norms and values from one generation to another.

\subsection{HIV/AIDS Situation in Tanzania}

Sub-Saharan Africa remains the region most affected by HIV. In 2013, Sub-Saharan Africa accounted for $70 \%$ of HIV 
infections worldwide. In 2008, more than 14.1 million children in Sub-Saharan Africa were estimated to have lost one or both parents to AIDS (UNAIDS, 2008). Tanzania like other sub-Saharan African countries is one of the most affected countries (TACAIDS, 2003). The current HIV prevalence in Tanzania is about 5.1 percent of the population aged 15-49 years (Tanzania HIV and Malaria Indicator Survey, 2012). The present data by THMIS (2012) also show that HIV prevalence in is higher in urban areas doubles that of rural areas. Among women, HIV prevalence is 8.9 percent in the urban compared with $5.1 \%$ in rural areas. For men, the corresponding prevalence is 5.2 percent and 3.4 percent for urban and rural areas respectively. Currently, regions with the highest number of cases in Tanzania as indicated in the surveillance report are Iringa, Mbeya and Dar es Salaam.

\subsection{Risky Sexual Behaviours and HIV/AIDS Knowledge among Young People in Tanzania}

In all populations, young people are the ones most at risk of HIV infection because they are the most sexually active group. For example, THMIS (2008) reported that 60 percent of young women and 44 percent of young men in Tanzania have had sex by the age of 18 . For example, primary and secondary school students were reported to marginalize their chances of being infected by thinking that HIV is a problem of other groups of people, such as barmaids, commercial sex workers, prostitutes and even peers who are out of school and engage in unsafe sexual practices (Kakoko, 2001). Studies show that young women in many parts of the developing world including Tanzania have little control over how, when, and where sex should take place and that, in the most extreme circumstances, young people living in stressful situations are forced to engage in sexual activity in order to meet their basic needs such as shelter, food, clothes and adult protection (Mboma, 2004; Samwel, 2006). Government statistics show that teenage pregnancy has become a matter of concern, especially among primary schoolgirls. For example, between 2000 and 2005 alone, more than 25,000 primary school girls dropped out of school due to pregnancy (Mkumbo, 2008). According to educational statistics (URT, 2009), between 2004 and 2008 alone, more than 17,000 primary schoolgirls and 11,599 secondary schoolgirls dropped out of schools due to pregnancy.

\subsection{HIV/AIDS and Life Skills Education Curriculum in Tanzanian School}

The significance of relevant content of HIV/AIDS and Life Skills education in the Tanzanian curriculum is that it will enable teenagers to develop self-awareness and to use the acquired knowledge to solve daily problems and challenges. However, Kirby, Obasi \& Laris (2006) argue that the choice and implementation of a school-based HIV/AIDS curriculum in poorer countries is constrained by the availability of teachers, together with lack of access to the necessary financial, material and technical resources. In addition, the culture and norms of local communities and the schools themselves may prohibit open discussion of sexual matters and actively discourage condom use in an attempt to promote abstinence. As well as having to compete in a crowded curriculum, the HIV/AIDS and Life Skills education programme does not have the same status as other subjects, either for pupils or teachers.

In part this is because it is usually non-examinable, but also because of the sensitive nature of the content, despite its potential importance for pupils' well-being. For teachers of HIV education there is rarely a tradition of advanced training. Teachers are sometimes instructed to give HIV education despite their lack of training, experience or interest. Taken together, these issues raise the question as to whether or not sex, relationships and HIV education is in need of professionalisation (Warwick et al., 2008).

HIV/AIDS and Life Skills education in the school curriculum in Tanzania has to be considered as having the potential to address young people's sexual health problems since it has not been well tapped. School policy makers have been reluctant to introduce sex education because of fear of parents' reaction (Mkumbo and Tungaraza, 2007). Nevertheless, evidence shows that well designed and executed school-based education can be effective in changing young people's sexual behaviour that leads to sexual health problems. The United Nations Population Fund (UNPF), UNICEF, UNESCO and the MoEVT through Tanzania Institute of Education (TIE) as executing and implementing agencies have financially and technically sponsored the life skills education initiatives. However, in the case of coverage it has not been well implemented due to the shortage of teachers (TIE, 2006) and inadequate research to reveal its coverage and delivery, consequently its effectiveness.

\subsection{Conceptual Framework}

The Context, Input, Process and Product (CIPP) evaluation model, developed by Stufflebeam (2000), was adopted as the conceptual framework that guided this study. The CIPP evaluation model stresses programme evaluation by assessing the quality of the plans, the extent to which the plans are carried out and the value of the outcome. The model adoption attempts to look at the effectiveness of the HIV/AIDS and Life Skills education programme from the view point of the context variable, which includes an assessment of the programme and explains the process involved and assesses the outcome of the programme. Therefore, based on the context of Stufflebeam model, it was derived for 
assessing the effectiveness of the HIV/AIDS and STDs, and Life Skills education deliver in primary schools in Tanzania. The major components of the conceptual framework are summarized in Figure 1.

Context

\begin{tabular}{|c|c|c|c|}
\hline & $\downarrow$ & $\downarrow$ & $\downarrow$ \\
\hline $\begin{array}{l}\text {-HIV Prevalence } \\
\text { and Policy } \\
\text {-Existence of } \\
\text { HIV/AIDS and } \\
\text { Pregnancies } \\
\text { affecting school } \\
\text { pupils } \\
\text {-Other risky } \\
\text { behaviours } \\
\text {-Values, } \\
\text { Attitudes, Beliefs } \\
\text { and norms } \\
\text {-Parents' or } \\
\text { guardians } \\
\text { 'educational } \\
\text { background } \\
\text {-Pupils' background } \\
\text { characteristics }\end{array}$ & $\begin{array}{l}\text {-Well trained and } \\
\text { motivated teachers } \\
\text { in terms of } \\
\text { knowledge, skills } \\
\text { and confidence } \\
\text {-Curriculum of } \\
\text { HIV/AIDS and Life } \\
\text { Skills Education } \\
\text { (Syllabus) } \\
\text {-Pupils in terms of } \\
\text { growth (maturation) } \\
\text {-External support } \\
\text { such as training, } \\
\text { workshops, } \\
\text { seminars etc } \\
\text {-Teaching \& } \\
\text { Learning materials } \\
\text {-Attitudes \& } \\
\text { Perception of the } \\
\text { community }\end{array}$ & 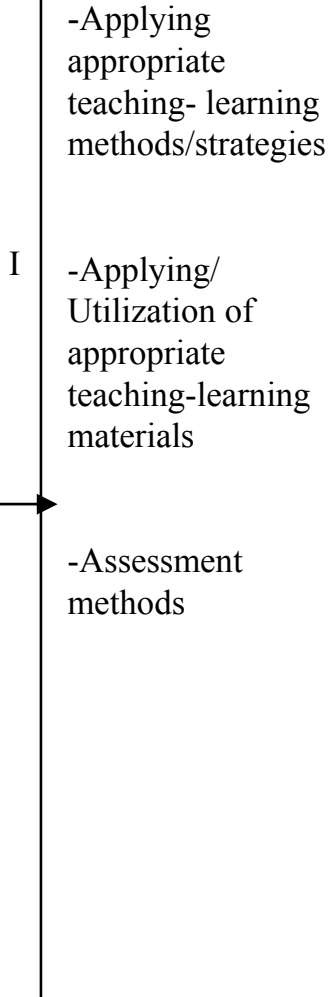 & $\begin{array}{l}\text {-Reduced number } \\
\text { of HIV/AIDS, } \\
\text { STDs and } \\
\text { Pregnancy cases } \\
\text {-Increased } \\
\text { Knowledge about } \\
\text { HIV/AIDS and Life } \\
\text { Skills Education } \\
\text {-Increased level of } \\
\text { Self-awareness } \\
\text {-Abstinence } \\
\text { developing and } \\
\text { sustaining sex } \\
\text { negotiation skills } \\
\text {-Perceived change } \\
\text { of behaviour }\end{array}$ \\
\hline
\end{tabular}

Figure 1. Conceptual Framework on the Level and Mode of HIV/AIDS and Life Skills Education

Source: Adopted from Stufflebeam Evaluation Model (2000)

\subsection{Empirical Findings}

According to the 2007 report of the Global HIV Prevention Working Group, globally, half or more of school attendees receive no school-based HIV education. Five to fifteen countries reporting to UNAIDS in 2006 said HIV education coverage in schools was below 15 percent. In all eighteen countries in which standardized health surveys were administered between 2001 and 2005, fewer than 50 percent of young people (15-24) had accurate knowledge about HIV (UNESCO, 2007). Kirby et al (2006) argue that the choice and implementation of school-based in poorer countries is constrained by the availability of teachers together with lack of access to necessary financial, material and technical resources. In addition, the culture and norms of local communities and schools themselves may prohibit open discussion of sexual matters and actively discourage condom use in an attempt to promote abstinence.

The study conducted in Uganda in 1997 revealed that girls engage in risky sexual behaviour because they lacked information on HIV/AIDS/STD and they also lack cash and employment opportunities (Bohmer et al 1997). It was concluded that when people do not know something about HIV often do not protect them because they lack the life skills or the means to adopt safe behaviours. Even people who know all the ways to prevent infection may be unable to change behaviour because of poverty or sexual violence.

Todd et al., (2004) conducted a study on sexual health education on pupils in primary schools in rural Tanzania. The study aimed at assessing pupils' knowledge and attitudes toward sexual health issues plus their sexual experiences. Findings revealed that pupils had inadequate knowledge since a high proportion of pupils were found to be in sexual active engagement. They also found out that pupils had inadequate reproductive health knowledge on preventing pregnancies and STDs, which put them at risk. The study done previously by Muhondwa in Tanzania (1999) revealed 
that majority of youth have their first sexual act at age group of 12-15 years. They even start earlier as young as 5years. Partners are usually of the same age although boys tend to be older. But sometimes girls have sex with much order persons. It was also reported that a few youths reach the age of 18 years without having had sex.

\subsection{Knowledge Gaps}

Little research has been done to assess the effectiveness of HIV/AIDS and Life skills education delivery in primary schools in Tanzania. The MoEVT has underscored the importance of HIV/AIDS and Life-Skills education in protecting young people from sexual health problems, including HIV/AIDS, and has issued guidelines for mainstreaming this education in the school curriculum. It is, however, not clear how much HIV/AIDS and Life Skills education is covered and how it is delivered in primary schools. This is the knowledge gap that this study attempted to bridge

\section{Methods}

\subsection{Approaches \& Design}

Both qualitative and quantitative research approaches were employed due to the nature of the data needed. The qualitative approach captured the feelings and opinions of pupils through open-ended questions, and helped in the analysis of the curriculum content using documentary search, while the quantitative approach presented the relationship between pupils' background characteristics and HIV/AIDS knowledge through closed questions. Patton (1990) points out that there is no single blueprint for planning research; therefore the study employed both qualitative and quantitative approaches that enabled the researcher to assess the level and model of HIV/AIDS and Life Skills education delivery in primary schools.

In this study, the descriptive survey research design was employed to accommodate the two approaches. This is because the survey design is one of the best suggested methods for measuring individuals' attitudes (Babbie, 2003). This study employed the descriptive survey design partly because it was also deemed important to collect in-depth information from primary school pupils of Morogoro Municipality. The study was a cross-sectional survey, because the researcher wanted to collect data from respondents of different social and demographic characteristics within the limited time available for the research.

\subsection{Study Area}

Morogoro Region was studied because it is one of the Tanzanian regions which are greatly affected by the problem of pupil/student pregnancies in both primary and secondary schools. According to national education statistics, 322 pupils dropped out of primary schools due to pregnancies in 2008 alone (URT, 2008), rendering the region with the highest incidence teenage pregnancy rates among primary school pupils in the country.

\subsection{Population, Sample and Sampling Techniques}

The target population of a sample is a large group of people, which has one or more characteristics in common, on which the researcher focuses (Kothari, 2004). The target population of this study was standard five, six and seven pupils of the selected schools in Morogoro Municipality, because these could provide the information required as they were grown up enough to express their ideas due to their age (9-16yrs).

According to Leedy (1986), the results from the sample can be used to make a generalization about the entire population as long as it is truly representative of the population. In this study, the sample selected for this study was based on Leedy's (2001) suggestion. Due to time constraints, a sample of 450 respondents was drawn from ten primary schools in Morogoro Municipality and in order for the study to be manageable. Table 2 presents the sample categories and their numbers.

Table 2. Summary of the Sample Categories $(\mathrm{N}=450)$

\begin{tabular}{lccc}
\hline \multicolumn{1}{c}{ Category of respondents } & \multicolumn{2}{c}{ Number of respondents } & Total \\
\cline { 2 - 3 } & Female & Male & \\
\hline Standard V & 82 & 70 & 152 \\
Standard VI & 78 & 73 & 151 \\
Standard VII & 77 & 70 & 147 \\
\hline Total & 237 & 213 & 450 \\
\hline
\end{tabular}

Source: Field data (2010) 


\subsection{Sampling Procedures}

The schools were selected through purposive sampling technique in order to have an equal number of schools from Morogoro Municipality. The method was deemed necessary for targeting respondents with the requisite information. Ten primary schools from seven wards were involved. The involvement of urban-based schools was considered important for this study due to the fact that studies conducted in Tanzania have shown that the spread of HIV/AIDS is much higher in urban settings than in rural ones (Lugoe, 1996). The researcher opted for government-owned schools only, for they were assumed to contain pupils with similar characteristics.

Pupils were selected through stratified random sampling on the basis of their stay in school, by including those in standard five, standard six, standard seven from each school, amounting to 450 pupils. They were selected because they were in the upper levels and it was assumed that they had adequate knowledge of and involvement in issues related to HIV/AIDS. Pupils were also stratified according to gender. After stratifying them into boys and girls, simple random sampling was employed to avoid bias, and have fifteen pupils from each class. Therefore, 45 pupils were selected from each school. The sampling was done separately for boys and for girls. Pieces of paper were written with either "yes" or "no". Boys had to pick papers, after which girls had to do the same. Those who picked papers with the world "yes" from both sides qualified to be involved in the sample. In simple random sampling, each member of the population under study has an equal chance of being selected (Cohen et al., 2003). In this respect each pupil had an equal chance of being selected.

\subsection{Data Collection}

Primary data are defined as original data collected from the field (Cohen et al., 2003). In this study, primary data were collected mainly through questionnaires while secondary data were collected through documentary search such as circulars/Guidelines for implementing HIV/AIDS and Life Skills education, pamphlets, newspapers/articles, books, Science and Social studies syllabuses and website materials. This type contained published or unpublished reports (Krishnaswami, 2002, p. 199).

\subsubsection{Data Collection Techniques}

\subsubsection{Questionnaires}

A questionnaire is the type of inquiry that is a data collection instrument through which respondents answer questions or respond to statements in writing (Best \& Kahn, 1993). Data were collected from pupils at their schools in order to find out the effectiveness of HIV/AIDS and Life Skills education delivery in primary schools. Self-completion structured questionnaires were used to collect data for this study and were opted because it was possible to collect adequate information from a large sample within a relatively short time while ensuring greater anonymity (Mark, 2004). Moreover, questionnaires were used because they maintain the confidentiality of the respondents, who are thereby stimulated to answer each statement in the instrument in a more favourable way. Studies like this capture well informants' opinions. These questionnaires were first constructed in English and then translated in to Kiswahili so that all the primary school pupils understand and respond to the questions well.

The questionnaires consisted of three parts. The first part of the questionnaire elicited data about the demographic characteristics of respondents such as sex, age, religion, class and parents' educational level, measured by 6 items.

The second part of the questionnaire consisted of questions which gathered data about pupils' views about HIV/AIDS and Life Skills teaching in primary schools, measured by 14 items. Respondents could designate these statements as true or false, or say they did not know. All correct answers were scored as 1; wrong and don't know answers were scored as 0 . However, 4 items in the second part gathered data about awareness of and involvement in HIV/AIDS services and activities. Both closed and open-ended questions were employed because the technique encourages greater honesty and a lot of information could be collected within a very short time.

The third part of the questionnaire consisted of questions which elicited data about pupils' knowledge about HIV/AIDS and related issues, which consisted of a test measured by 30 items. These items were in the form of a multiple choice test adopted from Yarber and Torabi (1991) HIV/AIDS knowledge questions with slight modification to suit the context. In this study the internal consistency, measured by Cronbach's alpha, was .88 which, according to Marks (2004), was considered to be reliable. This is in line with Pallant (2005) who argued that, if Cronbach's alpha coefficient is above .7, the scale is reliable.

\subsubsection{Documentary Search}

The information collected through the review of documents enabled the researcher to cross-check the consistency of the information collected through the questionnaires (Borg \& Gall, 1998). To add further light to this study, documents 
such as Guidelines for implementing HIV/AIDS and Life skills programme, circulars from MoEVT, teachers' schemes of works, lesson plans and lesson notes, logbooks, Science subject syllabus, Social Studies syllabus, conference reports, dissertations, pamphlets, journals, working documents from head teachers detailing cases of dropout due to HIV/AIDS and pregnancy, teachers' qualifications, educational materials (like teaching and learning materials and physical facilities), evaluation reports on HIV/AIDS and Life Skills education (school terminal and annual reports for science and social studies) were useful for exposing the reality about the HIV/AIDS policy, curriculum (content analysis) and teaching in schools.

\subsection{Data Analysis Procedures}

\subsubsection{Quantitative Data Analysis}

The Statistical Package for Social Sciences (SPSS) version 15 program was used to analyze quantitative data. Both descriptive and inferential statistics were used in data analysis. Collected data were edited, coded, classified into homogeneous groups and scored. Tables were used to summarize the study findings. Furthermore, the value of chi-square tests was used to compare the scores of each category measuring knowledge about HIV/AIDS and pupils' background characteristics (age, sex, religion, class and parents' educational level).

\subsubsection{Qualitative Data Analysis}

Information obtained from the documents reviewed and the open-ended questions in the questionnaire were summarized and subjected to content analysis. According to Achola (1995), content analysis refers to the research technique for systematic analysis of qualitative or quantitative data or both to manifest the latent meaning of words, phases, ideas, posture, objects or artifacts. Open-ended questions were categorized in order to get the differences from the two spatial settings.

\section{Results}

\subsection{Schools' and Respondents' Demographic Characteristics}

Four hundred and fifty (450) pupils completed the questionnaire. The survey was constructed to measure the effectiveness of the level and mode of HIV/AIDS and Life Skills education delivery in primary schools. Pupils from classes V, VI, and VII (age 9-16) were recruited from ten primary schools; their distribution for each school is shown in Table 3. For anonymity purposes, the actual names of the schools surveyed are not revealed; instead code names are used.

\subsection{Findings}

Table 3. Distribution of Respondents by Schools $(\mathrm{N}=450)$

\begin{tabular}{cccc}
\hline School & Male & Female & Total \\
\hline A & 24 & 21 & 45 \\
B & 27 & 18 & 45 \\
C & 19 & 26 & 45 \\
D & 25 & 20 & 45 \\
E & 23 & 22 & 45 \\
F & 20 & 25 & 45 \\
G & 15 & 30 & 45 \\
H & 19 & 26 & 45 \\
I & 21 & 24 & 45 \\
J & 20 & 25 & 45 \\
TOTAL & 213 & 237 & 450 \\
\hline
\end{tabular}

Source: Field data (2010)

450 pupils who completed the questionnaire, 33.8 percent were in Standard Five, 33.6 percent were in Standard Six and 32.7 percent were in Standard Seven. The majority of respondents were female (52.7\%). Participants ages ranged between 9 and 16 years, with the majority of them (54.7\%) ranging between 11 and 12 years. The majority of respondents were either Christians (60\%) or Muslims (38.7\%). The majority of the respondents stated that their parents'/guardians' educational levels in descending order were degree or above (13.6\%), certificate/diploma holders $(26.7 \%)$, secondary school leavers $(33.6 \%)$, primary education $(21.3 \%)$ and below primary education $(2.9 \%)$. 


\subsection{Pupils' Views about HIV/AIDS and Life Skills Teaching in Primary Schools}

Participants were provided with a list of 10 statements in second part of questionnaire assessing their views about the extent to which they had been given about HIV/AIDS. On average, 56.4 percent of respondents reported having been given HIV/AIDS and Life Skills education in school, while 41.5 percent reported that they had not. Furthermore, 2.1 percent of respondents were not sure whether or not they had been given HIV/AIDS and Life Skills education. When the specific contents were analysed, it showed that a majority (more than 75\%) reported having been taught about STDs, HIV/AIDS transmission and prevention modes. Condom use and decision making about sexual involvement had the least number of respondents reporting having been taught about them. Only 14 percent and 21.6 percent of respondents reported having been taught about condom use and decision making about sexual involvement respectively.

\subsection{Awareness of and Involvement in HIV/AIDS Services and Activities}

When respondents were asked if they knew where to obtain sexual and reproductive health services, only 33.8 percent of them responded in the affirmative, implying that a majority of pupils in the study area did not have information about and/or access to these services. Furthermore, almost none of the pupils were involved with HIV/AIDS education activities at school or in the community; less than five (5) percent of respondents reported that they were involved in HIV/AIDS education clubs at school or in the community.

\subsection{Pupils' Knowledge about HIV/AIDS and Related Issues}

In order to assess the effectiveness of HIV/AIDS and Life Skills teaching in primary schools, pupils were provided with 30 questions in part three of the questionnaire assessing their knowledge about HIV/AIDS. The questions were in the form of a multiple choice test, adopted from Yarber and Torabi (1991). 'HIV Prevention Knowledge Test for Teenagers' with slight modification to suit the context. The questions had a good reliability measure, with Cronbach's alpha of 0.88 . The questions were in five major categories, namely HIV transmission, HIV prevention, HIV infection, symptoms of HIV/AIDS and STDs, and HIV/AIDS testing and counselling. Each respondent's examination script was marked and graded accordingly. The possible scores could range between 0 (minimum) and 30 (maximum). All scores were then converted into percentages and graded according to the National Examinations Council of Tanzania criteria: with 0-20 (F)-Very Poor; 21-40 (D)-Poor; 41-60 (C)-Average; 61-80 (B)-Good and 81-100 (A)-Very Good. The results for each question are summarised in Figure 2.

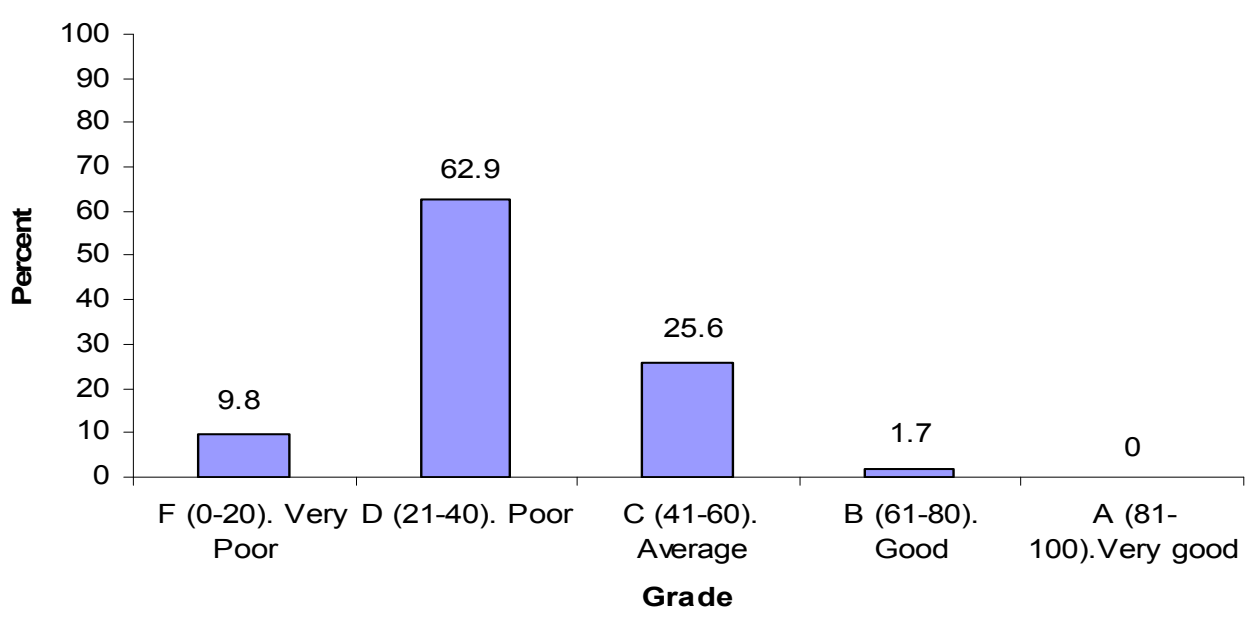

Figure 2. HIV/AIDS Knowledge Test Scores

Source: Field data (2010)

On average, as Figure 4.1 shows, majority of pupils demonstrated poor knowledge about HIV/AIDS, in that 72.7 percent of respondents scored between 21-40 percent (D) and 0-20 percent (F). Only 25.6 percent of respondents scored an average grade of $41-60$ percent $(C)$, while only 1.7 percent scored a B grade $(61-80 \%)$. None of the respondents scored Very Good (A grade).

In spite of the reportedly low level of knowledge about HIV/AIDS, the results of this study have shown that pupils have been taught some topics on HIV/AIDS and Life Skills such as HIV/AIDS infection and transmission. However, these questions are common in the mass media and pupils got over 50 percent, for example regarding the most common way 
HIV has been transmitted and about HIV infection. It is obvious that the knowledge they have did not depend only on classroom teaching but it came from different sources. This is in line with URT (2004) which stipulated that different Information, Education and Communication materials like Radio, TV, Newsletters and others shall be utilized in the dissemination of information to ensure successful implementation. Nevertheless, the results of this study have shown that pupils are not being taught some of the most critical topics in HIV/AIDS and Life Skills education, including HIV symptoms and prevention, contraceptives, condom use, multiple sex partners, sexual fidelity, selection of new sex partners, surest way to avoid HIV/AIDS and other STDs, HIV-antibody test and blood donation and blood transfusion.

\subsection{Effects of Pupils' Background Characteristics on their Knowledge about HIV/AIDS}

Chi-square tests were conducted to examine the effects of pupils' background characteristics on their level of knowledge about HIV/AIDS in different groups such as class level (standard V, VI, and VII), sex, age, religions and parents' educational levels. The results are summarized in Table 4.

Table 4. Effects of Pupils Background Characteristics on their Knowledge about HIV/AIDS

\begin{tabular}{lcccc}
\hline $\begin{array}{l}\text { Independent } \\
\text { Variable }\end{array}$ & $\mathrm{X}^{2}$ & $\mathrm{~N}$ & $\mathrm{df}$ & $P$ \\
\hline Class & 14.89 & 450 & 6 & .021 \\
Sex & 2.76 & 450 & 3 & .430 \\
Age & 23.95 & 450 & 18 & .157 \\
Religion & 5.97 & 450 & 9 & .743 \\
Parents' educational level & 40.48 & 450 & 15 & .004 \\
\hline
\end{tabular}

Source: Field data (2010)

As Table 4 shows, the results show that only class level and parents' educational level had a statistical significant effect on pupils' knowledge about HIV/AIDS and Life Skills. Standard Seven pupils demonstrated relatively higher knowledge (40.7\%) than Standard Six (32.6\%) and Standard Five (26.7\%). Pupils from parents with college or university education demonstrated higher knowledge (42.2\%) than those from secondary education level (36.7\%) and primary educational level $(17.6 \%)$ or below primary education level $(1.6 \%)$.

\subsection{HIV/AIDS Policy, Curriculum and Teaching in Schools}

Documents from HIV/AIDS and Life Skills education teachers like schemes of work, lesson plans, lesson notes, terminal and annual reports, reports on causes of dropout, teachers' qualifications and educational materials like physical facilities, different teaching and learning materials, syllabus and circular guidelines were reviewed in order to examine the involvement of pupils in different topics, the subject content and how the methods and content influenced pupils' behaviour and society as a whole. Information was sought through attendance registers, school discipline reports/books, monthly and annual school reports, daily duty report books to explore discipline matters, truancy, dropouts, pregnancies and other extra-curriculum activities carried out within school hours. Other information was sought from life skills textbooks, learning kits, brochures and Guidelines for implementing the HIV/AIDS and Life Skills Education programme in primary schools.

It was found out that the directives from the ministry responsible for education, in collaboration with Tanzania Institute of Education, on teaching the subject was for the teachers to integrate the content of HIV/AIDS and Life Skills education into other subjects that they taught. HIV/AIDS and Life Skills education in primary schools does not have its own independent subject syllabus, unlike other subjects such as Mathematics, Geography or Kiswahili, but its subject matter was to be integrated into other subject syllabi such as science and social science subjects. Teachers integrated HIV/AIDS and Life Skills education topics when teaching those other subjects. It was revealed that teachers used HIV/AIDS and Life Skills learners' kits, prepared by the Tanzania Institute of Education and NGO's, by selecting topics from the kit and integrating them in the major topics of other subjects. This means that no specific syllabus had been modified or transformed to accommodate HIV/AIDS and Life Skills education topics or content.

This, however, led to a lack of consistency and uniformity in integrating HIV/AIDS and life skills content, as every teacher integrated it according to his/her will and understanding of the topic to be taught instead of basing it on the directives they were given. The directives state that integrating HIV/AIDS and Life Skills content should be done based on the culture, environment and understanding of the pupils. This, however, was not easy. Problems such as lack of innovation and creativity in integrating HIV/AIDS and Life Skills subject matter into subject topics resulted in problems which hindered implementation of the Life Skills education project. Furthermore, the lack of teaching 
materials and textbooks for the programme as well as the poor knowledge of teachers in the delivery of HIV/AIDS and Life Skills education in school, which is central to this study, led to the ineffective delivery of HIV/AIDS and Life Skills education in primary schools. Additionally, teachers lack motivation for this extra role and enough time for the lesson in the period.

The findings obtained from the current Science and Social Study syllabuses in Tanzania showed that it covers only a small portion of HIV/AIDS and Life Skills knowledge. Furthermore, the little that is covered is usually factual material that is not accompanied by the necessary guidance and proper handling of young people's personal problems that are related to HIV/AIDS. Pupils supported the introduction of HIV/AIDS in the school curriculum in the hope that, apart from HIV/AIDS infections, it would help to alleviate many of their problems such as pregnancies, sexual promiscuity and STDs.

\section{Discussion}

\subsection{Pupils' Views about HIV/AIDS and Life Skills Teaching in Primary Schools}

The study has revealed that a substantial proportion of pupils are aware of what is covered in the curriculum regarding HIV/AIDS. Indeed, more than half of the pupils who completed the questionnaire reported that they have been taught about HIV/AIDS and Life Skills in their schools. Pupils reported having been taught four main topics on HIV/AIDS and Life Skills. These are HIV/AIDS transmission and prevention, Life skills education related to HIV/AIDS, puberty and Sexually Transmitted Diseases. Nevertheless, the results of this study have shown that pupils are not taught some of the most critical topics on HIV/AIDS and Life Skills, including contraceptives, condom use, reproduction and birth, and decision making regarding sexual activity in dating relationships. For example, only 14 percent of pupils reported having been taught on condom use, while less than 35 percent reported having been taught about decision making concerning sex. This is clearly a big gap in HIV/AIDS education because these topics are directly related to HIV/AIDS prevention and other sexual health problems such as pregnancy. As observed by Kirby et al (2006), Sex and HIV education helps to delay the initiation of intercourse, reduce the number of sex partners, increase the use of condom/contraception, and reduce unprotected sex, pregnancies and STI rates. Therefore, the current HIV/AIDS and Life Skills education in schools is not as effective as it should be.

\subsection{Awareness of and Involvement in HIV/AIDS Services and Activities}

The findings show that the majority of the pupils (66.2\%) do not know where they can get information and services about HIV/AIDS and reproductive health. The same was true of pupils' involvement in HIV/AIDS education clubs; less than 5 percent of pupils were involved in HIV/AIDS clubs either at school or in the community. The findings of this study are in line with a study conducted in Uganda in 1997, which revealed that girls engage in risky sexual behaviour because they lacked information on HIV/AIDS/STDs and they also lack cash and employment opportunities (Bohmer \& Kirumira, 1997). It was concluded that when people know little about HIV they often do not protect themselves because they lack the life skills or the means to adopt safe behaviours. Even people who know all the ways to prevent infection may be unable to change their behaviour because of poverty or sexual violence.

\subsection{Pupils' Knowledge related to HIV/AIDS and Life Skills Teaching in Primary Schools}

The findings reveal that a majority of the respondents had a very low level of knowledge about HIV/AIDS and Life Skills in primary schools in Tanzania. This means that only a small proportion of respondents have obtained a substantial amount of knowledge on HIV/AIDS, although these issues were covered in the school curriculum. The findings show that those who scored grade B in the test which was a good score comprised only $8(1.7 \%)$ respondents. Again, 115 (25.6\%) scored C an average mark. Interestingly, 293 (62.9\%) respondents scored D marked as poor and the remaining $44(9.8 \%)$ respondents scored very poorly.

The findings of this study are in line with those of other studies including of Oyo-Ita et al. (2005) that, although the level of awareness of HIV/AIDS is high among students, knowledge about the disease is very poor. Mass media as a source of information does not give in-depth knowledge about the disease. Parents, teachers and health workers should be more involved in educating the youth on this dreaded disease. Furthermore, according to the 2007 report of the Global HIV Prevention Working Group, globally, half or more of school attendees receive no school-based HIV education. Five to fifteen countries reporting to UNAIDS in 2006 said that HIV education coverage in schools was below 15 percent. In the eighteen countries in which standardized health surveys were administered between 2001 and 2005, fewer than 50 percent of young people (15-24) had accurate knowledge about HIV (UNAIDS, 2007). The situation apparently remains so among primary school population by the time of current study in 2011 . 


\subsection{Effects of Pupils' Background Characteristics and their Knowledge about HIV/AIDS}

The Chi-square test showed that there was a statistically significant difference between class level and HIV/AIDS knowledge, in which Standard VII demonstrated a higher level of knowledge than standard VI and standard VI has a higher level of knowledge than standard V. In our syllabus knowledge increased according to the level of education. This is supported by Mondea (2004) in his study measuring the level of HIV/AIDS knowledge among class levels which revealed that, standard VII pupils were found to have a higher level of knowledge than standard V and VI pupils in Ilemela and Magu districts (Mwanza region). However, the study done by Muhondwa in Tanzania (1999) revealed that a majority of youth engage in their first sexual act when aged between 10-15 years. They even start earlier as young as 5 years. Partners are usually of the same age although boys tend to be older. But sometimes girls have sex with much older persons. It was also reported that a few youths reach the age of 15 years without having had sex.

The results of this study have revealed a statistically significant effect of parental educational level on pupils' knowledge about HIV/AIDS. The findings are similar to those of Walker \& Smrekar (2002) who reported that, parents' level of education has been regarded as a predictor of children's academic achievement. Increasingly, research has suggested that, rather than having a direct association with children's academic achievement, parents' level of education is part of a larger constellation of psychological and sociological variables influencing children's school outcomes.

\section{Conclusions and Recommendations}

It is therefore recommended that teachers and service providers involved in HIV/AIDS prevention and counselling in primary schools should undergo regular training in programmes which would equip them with the relevant facts about HIV/AIDS so as to enable them to educate their pupils about the pandemic. Secondly, the Ministry of Education and Vocational Training should plan to have an HIV/AIDS and Life Skills syllabus as an independent subject like other subjects in the school curriculum. This will enable pupils to have it as a specific subject. Lastly, the study recommends that there is a need to improve HIV/AIDS and Life Skills education by reviewing the syllabus through conducting a needs assessment, as well as to improve the teaching methods that are used to deliver the subject matter. There is also a need to invest in a sensitizing campaign on HIV/AIDS and Life Skills education, targeting all people in the community. The teachers should know that there is a need to address the issue of sexual behaviour among pupils. Generally it should be noted that the role of addressing the sexual behaviour of pupils should not be left to the teachers only.

\section{Acknowledgements}

Prof. Kitila Mkumbo (University of Dar es Salaam, School of Education, Tanzania) for proof reading the article.

\section{References}

Achola, P. P. (1995). Content Analysis: Its Meaning, Uses and Misuses. In K. Mwikira \&S.P. Wamahiu (Eds.), Issues in education research in Africa. Nairobi: Eastern African Educational Publishers Ltd.

Babbie, E. (2003). The Practice of Social Research, (10th ed.). Belmont: CA. Thomson.

Best, J. W., \& Kahn, J. V. (1993). Research in Education, (7th ed). Chicago: Allyn and Bacon.

Bohmer, L., \& Kirumira, E. (1997). Access to reproductive health services: Participatory Research With Ugandan Adolescents for Control of STDs. Los Angeles: Pacific Institute for Women's Health. Retrieved from http://www.piwh.org/pdfs/uganda.pdf

Booler, T., \& Aggleton, P. (2005). Life Skills Education for HIV Prevention: A Critical Analysis. London: Save the Children and Action Aid International.

Borg, W. R., \& Gall, M. D. (1998). Educational Research: An Introduction. New York: Longman Inc.

Cohen, L., Manion, L. M., \& Morrison, K. (2003). Research Methods in Education, (5 ${ }^{\text {th }}$ ed.). London: Routledge Falmer.

Cresswell, J. W. (2008). Research Design: Qualitative, Quantitative and Mixed Methods Approaches, (3rd ed.). London: SAGE Publications Ltd.

Gay, L. R. (1981). Education Research Competencies for Analysis and Application. Columbia: Charles E. Merrill 
Publishing Company

Kakoko, D.C.V. (2001). The Relationship Between Health Perception and Condom useBehaviour Among Sexually Active Secondary School Students in Arusha, Tanzania. Unpublished M.A Dissertation: University of Dar es Salaam.

Kirby, D., Obasi, A., \& Laris, B. (2006). The Effectiveness of Sex Education and HIV Education Interventions in Schools in Developing Countries. In Ross, D., Dick, B, \& J. Ferguson (Eds.). Preventing HIV/AIDS in Young People: A Systematic Review of the Evidence From Developing Countries. Geneva: World Health Organization.

Kothari, R. C. (2004). Research Methodology: Methods and Techniques. New Delhi: Wiley Eastern Limited.

Krishnaswami, O. R. (2002). Methodology of Research in Social Sciences. New Delhi: Himalaya Publishing House.

Leedy, P. D. (1986). Practical Research: Planning and Design. Merrill: Prentice-Hall.

Leedy, P. D. (2001). Practical Research: Planning and Design. Upper Saddle River. Merrill: Prentice-Hall.

Lugoe, L. W. (1996). Prediction of Tanzania Students: HIV Risk and Preventive Behaviour. PhD Thesis. Norway: University of Bergen.

Marks, D. F. (2004). Questionnaires and Surveys. In D. F Marks \& L. Yardley (Eds.), Research Methods for Clinical and Health Psychology (pp. 122-144). London, Sage Publication.

Mboma, L.M.R. (2004). HIV/AIDS: An Economic and Social Challenge to Women in Tanzania. In A. Njau, \& T. Mruma (Eds.), Gender and Development in Tanzania. Past, Present and Future (pp. 257-278). Dar es Salaam, Women Research and Documentation Project.

Mbonile, L., \& Kayombo. E. J. (2008). Assessment of Parenting/ Guardians of Adolescents toward Introduction of Sex and Reproductive Health Education. East Africa Journal of Public Health Association, 5(1), 26-31.

Mkumbo, K., \& Tungaraza, F. D. (2007). Parents' Views and Attitudes Toward School Based Sex and Relationship Education in Rural and Urban Tanzania. Papers in Education and Development (Vol 27, pp 171-188). Dar es Salaam: Dar es Salaam University Press.

Mkumbo, K. (2008). An Exploration of the Psychosocial Factors Affecting the Development and Delivery of School-Based Sex and Relationships Education in Tanzania. PhD Thesis. England: University of Southampton.

Mondea, P. L. (2004). Assessment of HIV/AIDS Knowledge and Sexuality Among Primary School Youth in Mwanza Region. Unpublished MA Sociology Thesis. Tanzania: University of Dar es Salaam.

Muhondwa, E. P. Y. (1999). Adolescent Sexuality and HIV/AIDS in Mtwara Rural and Makete Districts. Report of a Study Commissioned by UNICEF - Tanzania (pp. 35-38).Unpublished.

Mwasandube, J. M. (1999). Life Skills Education in Mainland Tanzania Primary Schools: Its Appropriateness and Relevance to the World of Work. Unpublished MA Thesis. Tannzania: University of Dar es Salaam.

NACP. (2004). HIV/AIDS/STI Surveillance Report No. 19. Dar es Salaam: Government Press.

Oyo-Ita, A.E., Ikpeme, B. M., Etokidem, A. J., Offor, J. B., Okokon, E.O., \& Etuk, J. (2005). Knowledge of HIIV/AIDS among Secondary School Adolescents in Calabar (Vol. 4, No. 1, pp. 2-6). Nigeria: Annals of African Medicine Society.

Pallant, J. (2005). SPSS Survival Manual: A Step Guide to Data Analysis Using SPSS for Windows Version 15 (2nd ed.). New York: McGraw-Hill.

Patton, M. Q. (1990). Qualitative Evaluation and Research Methods. Newbury Park: Sage Publications.

Samwel, T. (2006). The Influence of Gender Based Socialization on HIV/AIDS Prevention among Young People in Magugu District. Unpublished Dissertation. Tanzania: University of Dar es Salaam.

Stufflebeam, D. L. (2000). The CIPP Model for Evaluation. In D. L Stufflebeam, G. F Madaus, \&T. Kellaghan (Eds.), Evaluation Models- chapter 16 (2nd ed.). Boston: Kluwer Academic Publishers.

Tanzania Commission for AIDS (TACAIDS). (2003). National Multi-Sectoral Framework on HIV/AIDS, 2003-2007: Prime Minister's Office.

Tanzania Commission for AIDS, National Bureau of Statistics, and ORC Marco. (2005). Tanzania HIV/AIDS Indicator Survey 2003-2004. Calverton, MD: TACAIDS, NBS, and ORC Marco.

THMIS. (2012). Tanzania HIV/AIDS and Malaria Indicator Survey 2011-2012; Preliminary Report. 
Todd, J., Changalucha, S., Ross, D.A., Mosha F., Obass A., Plummer, M., \& Balira R., et al. (2004). The Sexual health of Pupils in years 4 to 6 Primary Schools in Rural Tanzania. Us National Library of Medicine, 80(1), 35-42.

UNAIDS (2013). AIDS Epidemic Update. Geneva: UNAIDS.

UNAIDS and World Health Organisation. (2007). AIDS Epidemic Update: December 2007. Geneva, Switzerland: Joint United Nations Programme on IV/AIDS and WHO.

UNAIDS and World Health Organisation. (2013). Report on the Global HIV/AIDS Epidemic Update. Geneva: UNAIDS/WHO

UNAIDS and World Health Organisation. (2014). Report on the Global HIV/AIDS Epidemic Update. Geneva: UNAIDS/WHO.

UNAIDS. (2007). Comparing Adult Antenatal-Clinic Based HIV Prevalence with Prevalence from National Population Based Surveys in Sub-Saharan Africa. Retrived from http://data.unaids.org/pub/Presentation/2007/survey_anc_2007_en.pdf

UNAIDS. (2008). AIDS Epidemic Update. Geneva: UNAIDS.

UNESCO (2007). EFA Global Monitoring Report: Strong Foundations- Early Childhood Care \& Education. France: United Nations Educational, Scientific and Cultural organization.

UNESCO (2009). Focusing Resources on Effective School Health Education. Retrieved from http://portal.unesco.org/education/en//php-URL

United Republic of Tanzania (URT). (2001). National Policy on HIV/AIDS. Dar es Salaam: Prime Minister's Office

United Republic of Tanzania (URT). (2004). Basic Education Statistics in Tanzania, Regional Data. Dar es Salaam, Tanzania: MoEVT.

United Republic of Tanzania (URT). (2004). Guidelines for Implementing HIV/AIDS and Life-Sills Education Programme. Dar es Salaam: Ministry of Education and Culture.

United Republic of Tanzania (URT). (2009). Basic Education and Statistics in Tanzania (BEST) 2005 - 2008). National and Regional Data. Dar es Salaam: MOEVT.

Walker, J. M. T., \& Smreker, C. (2002). Parenting: Influence of Parents' Level of Education. Retrieved from http://www.answers.com/topic/parenting-influence-of-parents-level-of-education

Warwick, I., Maxwell, C., Statham, J., Aggleton, P., \& Simon, A. (2008). 'Supporting Mental Health and Emotional Well-Being among Younger Students in Further Education', Thomas Coram Research Unit, Institute of Education, University of London: Journal of Further and Higher Education, 32, 1-13. Retrieved from http://www.pdfserve.informaworld.com/737307 918011756_ 789871597.pdf

Yarber, W. L., \& Torabi, M. (1991). HIV Prevention Knowledge Test for Teenagers. SIECUS Report, 19(2), 28-32. 